Die Berliner

Akademie

der Wissenschaften

in der Zeit

des Imperialismus

Teil II

I9I7-I933 
STUDIEN ZUR GESCHICHTE

DER AKADEMIE DER WISSENSCHAFTEN DER DDR

Band 2/II

Herausgegeben im Auftrage des Präsidenten der Akademie der Wissenschaften der DDR von Heinrich Scheel

FORSCHUNGSSTELLE

FUR DIE GESCHICHTE DER AKADEMIE

LEITER: LEO STERN 


\section{Die Berliner}

\section{Akademie}

der Wissenschaften

\section{in der Zeit}

\section{des Imperialismus}

\section{Teil II}

Von der Großen

Sozialistischen

Oktoberrevolution

bis 1933
Unter Mitarbeit

des Kollektivs

der Forschungsstelle

verfaßt von

Wolfgang Schlicker

Leitung der Arbeiten und Gesamtredaktion

Leo Stern

AKADEMIE-VERLAG BERLIN 
Erschienen im Akademie-Verlag, 108 Berlin, Leipziger Straße 3-4

(C) Akademie-Verlag, Berlin 1975

Lizenznummer: $202 \cdot 100 / 262 / 75$

Einband und Schutzumschlag: Rolf Kunze

Gesamtherstellung: VEB Druckerei „Thomas Müntzer“ 582 Bad Langensalza

Bestellnummer: 7528144 (2168/2/II) - LSV 0205

Printed in GDR

EVP 48,- 